\title{
Sustainability in project-based learning: Project themes and self- perceived competencies
}

T. Bolstad, L. Lundheim, M. Orlandic, and A. Strømberg, Department of Electronic Systems, NTNU

\section{P. H. Zimmermann, Department of Computer Science, NTNU}

\begin{abstract}
Project-based learning can be a suitable arena in which to integrate sustainability. In this work, we study what effect choosing a project theme related to sustainability has on the students' own assessment of integration of sustainability aspects in their projects, and their development of the normative, critical thinking, and self-awareness competencies from UNESCO's key competencies for sustainability. It is found that while having sustainability-related project themes does have some effect, the effect is limited compared to the development of other competencies in the course.
\end{abstract}

\section{INTRODUCTION}

Including sustainability in higher education has grown significantly in importance in the last years. In order to include sustainability without reducing other areas of the curriculum, it is often proposed to integrate the theme in existing courses, thereby achieving dual use of time [1]. However, it is not necessarily clear for study program administrators and course coordinators how to effectively integrate sustainability aspects [2]. In courses oriented around project-based learning (PBL), students are often expected, to some degree, to generate knowledge and competencies through interaction with the project, without targeted learning activities. For example, in the electrical engineering oriented PBL courses studied here, the students are partly expected to learn about electrical engineering through working on the project through self-directed learning [3]. In this work, we investigate the effect of having themes related to sustainability in a PBL course and whether this is sufficient to develop sustainability-related competencies.

Our enquiry is based on UNESCO's key competencies for sustainability [4]. Specifically, we look at the students' own assessments of whether sustainability-related projects stimulate the utilization and development of the normative, critical thinking, and self-awareness competencies, descriptions of which can be found in Table 1. Through these self-assessments we can compare the effects of the different project themes and consider whether sustainability-related themes are an effective way of integrating sustainability in a PBL-course. These competencies were chosen as they do not overlap with intended learning outcomes already included in the investigated courses.

At the 5-year integrated master's program Electronic Systems Design and Innovation (Elsys) at the Norwegian University of Science and Technology, NTNU, the students participate in courses oriented around PBL in the first and fourth semester $[5,6]$. In these courses, the students collaborate in groups on a project, the specifics of which are to a large degree defined by the students themselves, within a predefined theme or setting. The theme given to the students changes every year and some of these have been more directly linked to sustainability than others.

The current students at the study program have been involved in a total of five different innovation projects [7]. Intuitively, the projects can be divided into two groups, with three projects having themes more related to sustainability than the remaining two. The project related to sustainability were focused on water quality in local rivers, effects of windmills on the local environment, and infrastructure for walking and biking, respectively. The other two projects were related to the new offices of a local newspaper and the sport curling, respectively. This creates a basis for comparison of the effect of the theme on students' development in these courses.

\section{METHODS}

A survey was distributed through mailing lists to all active students at the Elsys study program. The survey was open from $20^{\text {th }}$ of November 2020 through the $8^{\text {th }}$ of December 2020 . Two follow up reminders encouraging the students to participate were sent in that period. No data that could identify the person participating were collected, therefore is it possible that one person could complete the survey several times. The survey had 31 items that required a response and covered their views on the projects' 
relation to sustainability, integration of sustainability in their projects, and assessment of their development of sustainability-related competencies. Additionally, to enable comparisons, some questions were asked related to a set of competencies in the intended learning outcomes for the courses, given in Table 1.

Table 1: The key competencies for sustainability studied in this paper (first three rows) [4] and competencies related to the courses (last row). The letters and number inside the parentheses refer to the codes used in presentation of the survey results.

\begin{tabular}{|l|l|}
\hline Competency & Description \\
\hline $\begin{array}{l}\text { Normative } \\
\text { competency }\end{array}$ & $\begin{array}{l}\text { the abilities to understand and reflect on the norms and values that underlie one's actions } \\
\text { (N1); and to negotiate sustainability values, principles, goals, and targets, in a context of } \\
\text { conflicts of interests and trade-offs, uncertain knowledge and contradictions (N2). }\end{array}$ \\
\hline $\begin{array}{l}\text { Critical thinking } \\
\text { competency }\end{array}$ & $\begin{array}{l}\text { the ability to question norms, practices, opinions and established theories (CT1); to reflect } \\
\text { on own one's values, perceptions, perspectives and actions (CT2); and to take a position } \\
\text { in the sustainability discourse (CT3). }\end{array}$ \\
\hline $\begin{array}{l}\text { Self-awareness } \\
\text { competency }\end{array}$ & $\begin{array}{l}\text { the ability to reflect on one's own role in the local community and (global) society (SA1); } \\
\text { to continually evaluate and further motivate one's actions (SA2); and to deal with one's } \\
\text { feelings and desires (SA3). }\end{array}$ \\
\hline $\begin{array}{l}\text { Course intended } \\
\text { learning outcomes }\end{array}$ & $\begin{array}{l}\text { the ability to break down complex problems into simpler parts (PBL1); the ability to } \\
\text { collaborate with others (PBL2); planning an extended complex project (PBL3); } \\
\text { completing an extended complex project (PBL4). }\end{array}$ \\
\hline
\end{tabular}

Out of the 377 students at the study program, 135 participated in the survey and agreed to let the data be used in this project, giving a total response rate of $36 \%$. The number of respondents for the $1^{\text {st }}$ to $5^{\text {th }}$ year of study were, $45(42 \%), 26(31 \%), 27(37 \%), 21(34 \%)$ and $15(29 \%)$, respectively, with the response rate for each year given in the parentheses. Additionally, there was one respondent who has dropped a year and participated in a project before 2015. This student will be disregarded when looking at correlations between project themes and responses. Generally, it has been shown that when looking at a sample of this size, this response rate will produce very few instances of mean errors over 0.3 standard deviations [8], though the chance of errors will be larger when looking at smaller subsets of the sample.

The email invitation to the survey revealed the theme of the survey, therefore there might be a bias of the respondents towards students with an interest in sustainability. A higher rate of response from female students was observed. Out of all respondents, $37 \%$ were female, $61,5 \%$ male and $1.5 \%$ did not want to give their gender. The study program overall has $29 \%$ female students.

The survey utilizes a seven-point Likert scale, mapped onto a numerical 1-7 point scale to allow statistical analysis. Low values correspond to options such as strongly disagree or to a very small degree and vice versa for high values. In order to reveal statistically significant differences between the groups studied, Welch's t-test has been used when looking at two groups and ANOVA when looking at more than two groups. A significance level of 0.05 was used in this work. While Likert scale data is ordinal and does not strictly follow a normal distribution, it has been found that these parametric tests are as suitable for Likert scale analysis as non-parametric tests $[9,10]$.

\section{RESULTS}

The students were asked whether the project they had participated in was related to sustainability. Sustainability in general or in engineering education were not defined in the survey. None of the students in the projects in 2016 and 2019 answered that their project was related to sustainability. For the three other projects, $95 \%, 89 \%$, and $98 \%$ responded a relation to sustainability for the years 2017,2018 , and 2020 , respectively. This is largely in line with our earlier intuitive assumption. The slightly lower rate for 2018 might be due to the fact that the project was related to windmills, whose contribution to a sustainable society was a highly debated topic in national media at the time. However, a one-way ANOVA test does not show that these results for 2017, 2018, and 2020 are statistically different. Thus, the following results are grouped based on their theme's relation to sustainability. No statistically significant differences within these groups were found except where commented. 
Sustainability is often represented as consisting of three domains or pillars: economic, environmental, and social. When asked which of these pillars they think about when hearing the terms "sustainability" and "sustainable development", 35\%, 100\%, and 20\% (multiple choices were possible) of the respondents answered economic, environmental, and social sustainability, respectively. It is clear that the students most strongly associate sustainability with environmental issues, and this suggests that inclusion of sustainability in education has to have environmental sustainability as a leading element in order to meet the expectation of the students. This question was asked towards the end of the survey to try to avoid priming the respondents' responses to the questions regarding sustainability in their projects.

The students were asked to assess the degree to which they took into account or reflected on sustainability in different phases of their project: problem formulation, design, implementation, verification and test, and end results. The means of the results grouped by the projects' relation to sustainability are shown in Figure 1. In all cases, sustainability was taken into account or reflected on to a larger degree in the projects related to sustainability with differences that are statistically significant. Though higher, in all cases the averages are near the neutral option, 4.

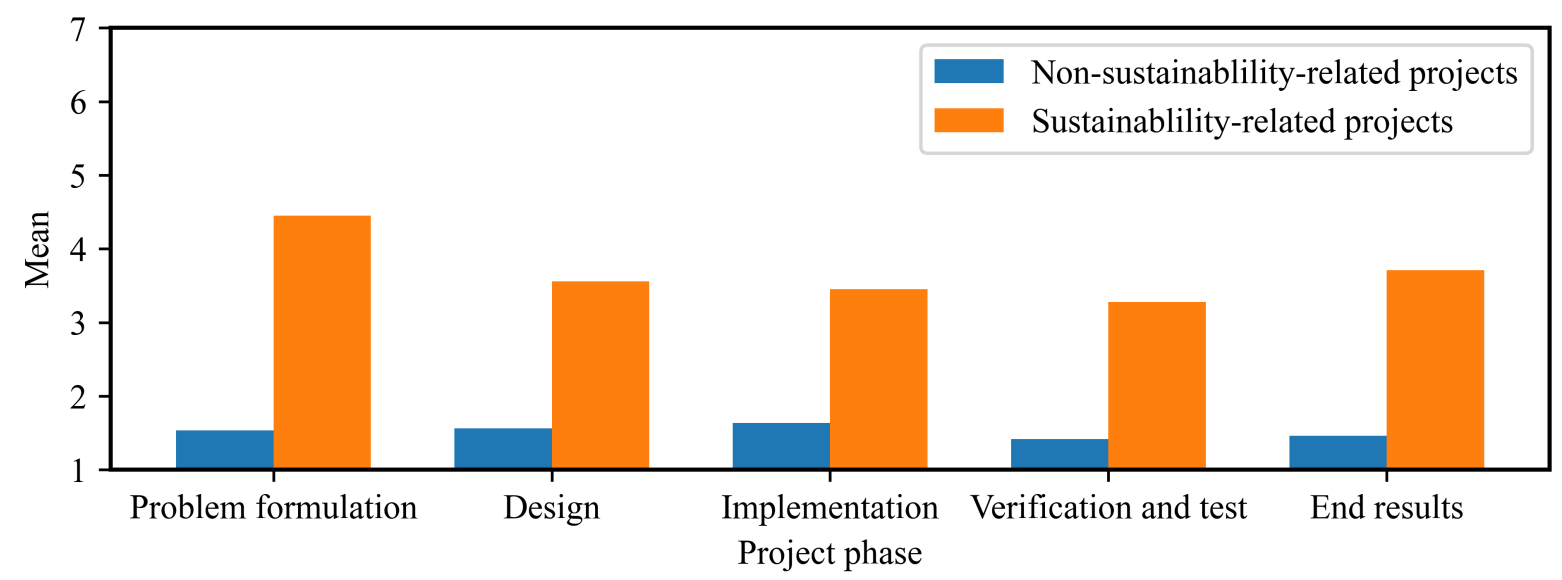

Figure 1: The mean of the degree to which the students reported that they took into account or reflected on sustainability in different phases of their project. The results are grouped based on the project themes relation to sustainability.

In Figure 2 the students' assessment of whether the course contributed to the development of selected competencies is shown. Questions labeled $N, C T$, and $S A$ refer to the normative, critical thinking, and self-awareness competencies, respectively. The questions labeled $P B L$ are related to competencies in the intended learning outcomes of the courses explicit learning activities such as the ability to collaborate with others, break down complex problems, and plan and complete a project. These can be seen in Table 1 .

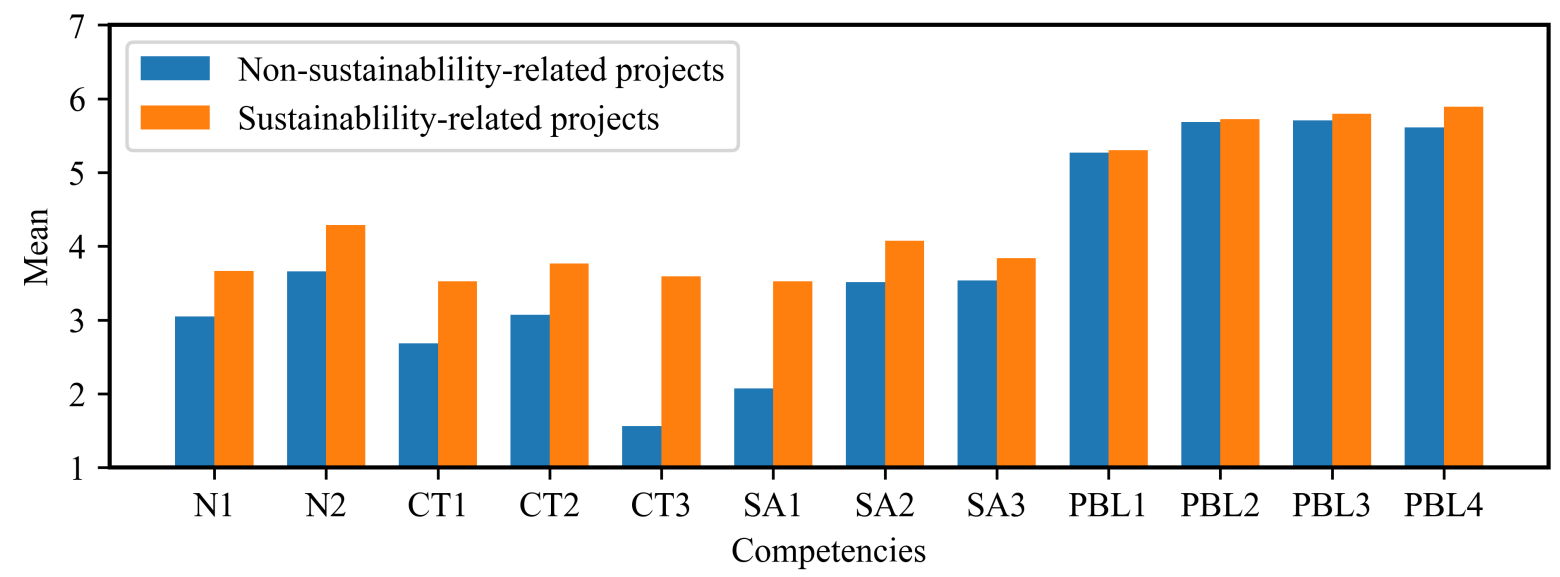

Figure 2: The mean of the students' assessment of the degree to which they developed skills within the 12 competencies. The competencies labeled $N, C T$ and SA are related to UNESCO's key competencies for sustainability, and the competencies labeled $P B L$ are related to learning activities in the courses as can be seen in Table 1. 
The differences observed for the sustainability and non-sustainability-related projects are statistically significant except for SA3 and PBL1-4. That the differences for these last four competencies are not statically significant indicates that the development of these competencies is independent of project theme and enables the use of these as a benchmark for comparison.

With regards to the normative, critical thinking, and self-awareness competencies, the measured averages are in all cases higher for the sustainability-related projects. The largest differences are found for CT3 taking a position in the sustainability discourse and SA1 reflect on one's own role in the local community and society. With respect to the sustainability-related projects, the averages for these competencies are close to the neutral option 4, significantly lower than the competencies with explicit learning activities.

Similar to the results shown previously in Figure 1, having a project theme related to sustainability does, according to the students' own assessment, increase the development of these competencies compared to a project without a theme related to sustainability, except for the case of SA3 deal with one's own feelings and desires. However, also here the development does not happen to any large degree as can be seen both with respect to the scale and the competencies assumed to be developed through learning activities.

The students were also asked about their views on sustainability and sustainability in education with questions labeled $S$ being general questions and $S E$ concerning the Elsys program specifically. The questions are given in Table 2 and the results are shown in Figure 3. With regards to the differences between projects related and not related to sustainability, only question $S E 2$ has statistically significant differences. The students who have participated in a project with a theme related to sustainability reported to a larger degree that there is enough focus on sustainability at Elsys.

Table 2: Questions and statements oriented around the importance of sustainability and sustainability education. The letters and number inside the parentheses refer to the codes used in Figure 3 and text.

\begin{tabular}{|l|}
\hline Question/statement \\
\hline How much to you care about sustainability and sustainable development $(S 1)$ ? \\
\hline It is important that sustainability is a part of education in general $(S 2)$. \\
\hline An engineer should consider the sustainability consequences of their work $(S 3)$. \\
\hline It is important that sustainability is a part of education at Elsys (SE1). \\
\hline There is a sufficient focus on sustainability at Elsys as a whole (SE2). \\
\hline What exists of sustainability focus at Elsys is done in the right way (SE3). \\
\hline
\end{tabular}

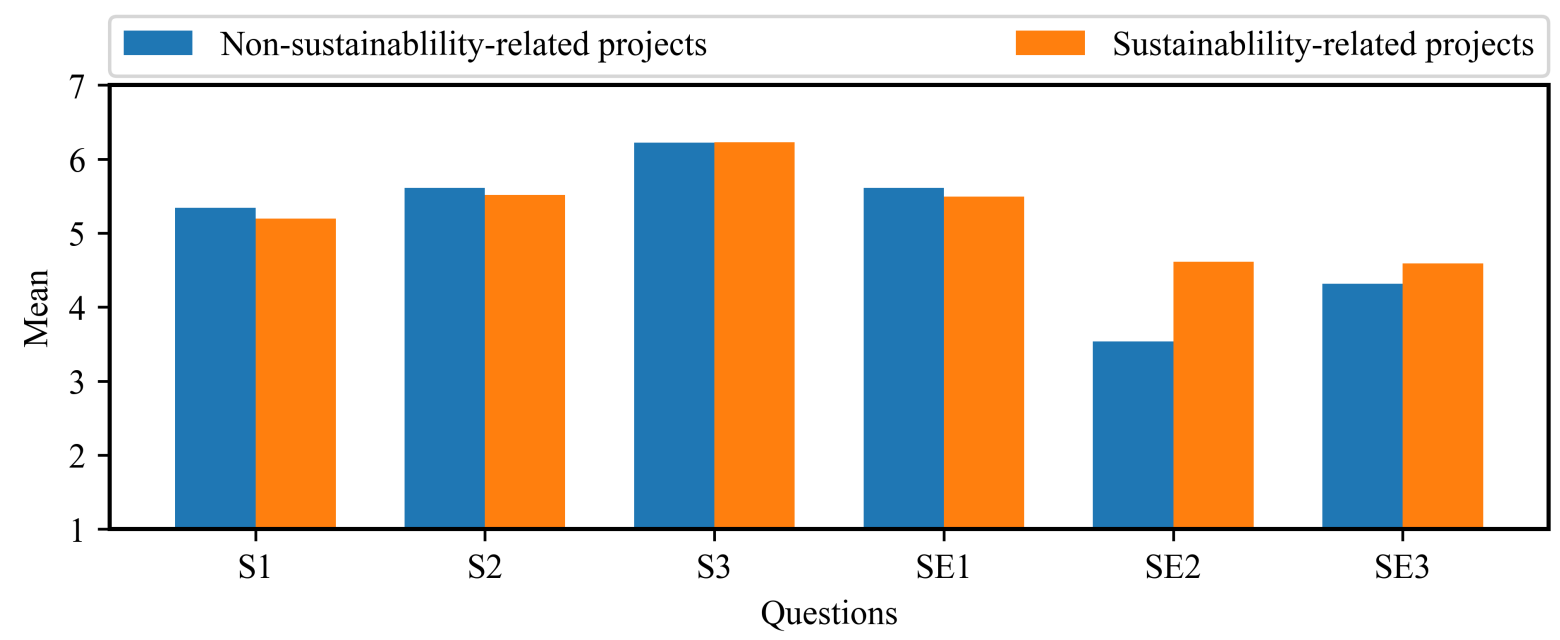

Figure 3: The mean of the students' views on the importance of sustainability in general, labeled $S$, and for Elsys specifically, labeled $S E$. The questions are shown in Table 2.

As observed from questions $S 1$ and $S 2$, the students care about sustainability and think that it is important for sustainability to be a part of education in general, respectively. They also believe that it is important 
for sustainability to be a part of the Elsys program specifically as observed from question $S E 1$. In addition, the students report that they think that an engineer should evaluate the sustainability ramifications of their work as shown from question $S 3$. For this question $51 \%$ of the respondents chose 7 , strongly agree. In the questions labeled $S 1-3$ there was a statistically significant difference between the projects. The 2017 project had a lower mean value than the others. The reason for this has not been investigated further.

With regards to the current integration of sustainability at the Elsys study program, the students to a lesser degree agree that there is enough focus on sustainability, $S E 2$, and that the existing focus on sustainability is done correctly, SE3. A potential issue with these questions is that there is limited focus on sustainability in most similar study programs at the university. Therefore, the students might have a limited perspective on what sustainability in engineering education looks like or what it could look like.

\section{DISCUSSION AND CONCLUSION}

The results indicate that having a theme related to sustainability does generate some considerations of sustainability in the students' projects and some development of sustainability competencies compared to other themes as seen from Figures 1 and 2, however limited compared to other competencies developed in the courses.

PBL courses can be an arena for the development of self-directed learning [3] and be well suited for integration of sustainability competencies, especially as common intended learning outcomes in PBL courses overlap with many of UNESCO's key competencies for sustainability [11]. Here we observe that, even though the students are interested in sustainability and think sustainability is important for an engineer to consider, this is not, along with a sustainability-related theme, sufficient to generate learning with regards to the normative, critical thinking, and self-awareness competencies to a large degree. We believe targeted activities addressing sustainability along with well-designed assessment is needed in order to sufficiently incentivize the students' development of these competencies, in line with Biggs' model of constructive alignment [12]. This should be a target of research for future studies along with further investigation of the students' perspectives on sustainability in electrical engineering education.

\section{REFERENCES}

1. Bærekraftig kompetanse, Delrapport 1, Fremtidens teknologistudier. 2020, NTNU.

2. Thürer, M., et al., A systematic review of the literature on integrating sustainability into engineering curricula. Journal of Cleaner Production, 2018. 181: p. 608-617.

3. Loyens, S.M., J. Magda, and R.M. Rikers, Self-directed learning in problem-based learning and its relationships with self-regulated learning. Educational Psychology Review, 2008. 20(4): p. 411-427.

4. Education for sustainable development goals: Learning objectives. 2017, UNESCO Publishing.

5. Lundheim, L., et al. Early innovation projects: First experiences from the electronic engineering ladder at NTNU. in 12th International CDIO Conference. 2016. Turku, Finland.

6. Bolstad, T., et al., Emergent premises in student experiences of a first-year electrical engineering course. European Journal of Engineering Education, 2020: p. 1-16.

7. Innovasjonsprosjektet. [cited 2021 Jan]; Available from: https://www.ntnu.no/studier/mtelsys/innovasjonsprosjektet.

8. Fosnacht, K., et al., How important are high response rates for college surveys? The Review of Higher Education, 2017. 40(2): p. 245-265.

9. De Winter, J. and D. Dodou, Five-Point Likert Items: $t$ test versus Mann-Whitney-Wilcoxon (Addendum added October 2012). Practical Assessment, Research, and Evaluation, 2010. 15(1): p. 11.

10. Sullivan, G.M. and A.R. Artino Jr, Analyzing and interpreting data from Likert-type scales. Journal of graduate medical education, 2013. 5(4): p. 541-542.

11. Guerra, A., Integration of sustainability in engineering education. Why is PBL an answer? International Journal of Sustainability in Higher Education, 2017. 18(3): p. 436-454.

12. Biggs, J.B. and C. Tang, Teaching for quality learning at university. 4th ed. 2011, Berkshire: McGraw-Hill Education. 